\title{
Gezgin Satıcı Problemi İçin Yeni Bir Çözüm Yaklaşımı: TPORT
}

\author{
A Novel Solution Approach for Travelling Salesman \\ Problem: TPORT \\ Kenan Karagül $1^{*}$
}

${ }^{1}$ Pamukkale Üniversitesi, Honaz Meslek Yüksekokulu, Yönetim ve Organizasyon Bölümü, Denizli, TÜRKIYE Sorumlu Yazar / Corresponding Author*: kkaragul@pau.edu.tr

$\ddot{\mathbf{O z}}$

Bu çalışmada, yöneylem araştırması alanının en çok çalışılan problemlerden biri olan gezgin satıcı ve ulaştırma problemleri üzerinde durulmakta ve aralarındaki ilişkiden faydalanan yeni bir çözüm algoritması önerilmektedir. Ulaştırma problemleri için bir çok başlangıç çözüm algoritması önerilmiştir. Benzer bir mantık ve sezgi ile simetrik gezgin satıcı problemine başlangıç çözümü üretmek için TPORT adı verilen bir yaklașım önerilmiștir. Bu yöntem gezgin satıcı problemini daha etkin çözmek için yıllardır süren araştırmalara bir katkı sağlamak için önerilmiştir. Önerilen yöntemde gezgin satıcı uzaklık matrisi, bir ulaştırma tablosu gibi ele alınarak, matris üzerinde yapılan özel bir normalizasyon işlemi ile gezgin satıcı problemi için başlangıç çözümü elde edilmektedir. Daha sonra, elde edilen başlangıç çözümünün performansı 2-0pt algoritması ile geliştirilmektedir. Geliștirilen sezgisel, En Yakın Komşu algoritması ile yakınlık gösterdiği için gezgin satıcı problemlerinin çözüm performansları En Yakın Komşu algoritması ve doğrudan başlangıç çözümüne uygulanan 2-Opt algoritması sezgisellerinin çözümleri ile karşılaștırılmıştır. Önerilen yaklaşım sıklıkla kullanılan gezgin satıcı test problemleri ve bilimsel yazında yer alan bir grup problem ile analiz edilmiştir. Ortalama çözüm değeri optimalden \%26 sapma gösterirken, En Yakın Komşu algoritması için optimalden sapma \%16 olarak gerçekleşmiştir. Ancak 2-0pt ile hem TPORT hem de En Yakın Komşu algoritmalarının çözümleri geliştirildiğinde, sırasıyla \%4 ve \%3 optimalden ortalama sapma elde edilmiștir. Bu bağlamda önerilen çözüm yaklaşımının çözüm performansı açısından rekabetçi olduğu ileri sürülebilir. Ayrıca çözüm süreleri açısından yapılan karşılaştırmalarda önerilen yöntemle En Yakın Komşu algoritması arasında önemli düzeyde fark vardır. Sonuç olarak, önerilen yöntemin çözüm hızı açısından üstün, çözüm kalitesi bakımından kıyaslanan yöntemlere göre rekabetçi olduğu gösterilmiştir. Özellikle, problem boyutu büyüdükçe klyaslanan yöntemlerin çözüm süresi neredeyse sabit bir seviyede seyrederken En Yakın Komşu algoritmasının çözüm süreleri üstel bir eğilim göstermiștir.

Anahtar Kelimeler:Gezgin Satıcı Problemi, Ulaştırma Problemi, En Yakın Komşu Algoritması, 2-Opt Algoritması

\section{Abstract}

In this study, one of the most frequently studied problems in the field of operations research, the traveling salesman problem and the transportation problem, are considered, and a new solution algorithm that takes advantage of the relationship between them is proposed. Many initial solution algorithms have been proposed for transportation problems. In this study, with a similar approach 
and intuition, an approach called TPORT is proposed for the initial solution of the symmetric traveling salesman problem. This method has been proposed to contribute to years of research to solve the traveling salesman problem more effectively. In the proposed method, the traveling salesman distance matrix is treated as a transportation table, and a special normalization process on the matrix provides the initial solution of the traveling salesman problem. Then, the performance of the initial solutions is improved with 2-Opt algorithm. As the developed heuristic has similarities with the nearest neighbor algorithm, the solution performances of the traveling salesman problems were compared with the solutions of the nearest neighbor algorithm and the solutions of the directly applied 2-Opt algorithm. The proposed approach has been analyzed by the well-known traveling salesman test instances and a group of test instances from the literature. The average solution performance of the proposed method has $26 \%$ deviation from the optimal, whereas the performance of the nearest neighbor algorithm has a $16 \%$ deviation from the optimal. However, when the solutions of TPORT and nearest neighbor algorithm were improved with 2-Opt, the average deviation was obtained as $4 \%$ and $3 \%$, respectively. In this context, it can be argued that the proposed solution approach is competitive in terms of solution performance. Also, there is a huge difference between the proposed method and the nearest neighbor algorithm in terms of solution times. As a result, it has been shown that the proposed method is superior in terms of solution speed and competitive in terms of solution quality. In particular, as the problem size is increased, the solution time of the comparable methods is almost constant, while the solution time of the nearest neighbor algorithm shows an exponential increasing trend.

Keywords: Traveling Salesman Problem, Transportation Problem, Nearest Neigbor Algortithm, 2-Opt Algorithm

\section{Giriş}

Ulaştırma problemi (UP), m adet kaynaktan n adet talep noktasına ürünlerin en az maliyetle dağıtımının planlanması problemidir. Atama problemi (AP) ise tek kişi sadece tek işe atanmak üzere, $\mathrm{n}$ adet işe $\mathrm{n}$ adet kişinin en az maliyetle atanması problemini ifade eder [1-4] UP ve AP birbiriyle benzer șekilde ele alınan, yakın ilișkili problemlerdir. Genel olarak bakıldığında her iki problem de kapasiteli ağ akış probleminin özel türüdür [5]. Diğer taraftan, yine bilimsel yazında çok çalışılan ve temel yöneylem araştırması problemlerinden biri olan gezgin satıcı problemi (GSP) yukarıda bahsedilen problemler ile büyük oranda benzerlik gösterir. $\mathrm{Bu}$ bağlamda Ulaştırma, Atama ve GSP arasında önemli teorik ilișkiler olduğu ileri sürülebilir [3].

Günümüzde gerek araştırmacılar gerekse endüstriyel uygulayıcılar GSP için hızlı ve etkin çözümler üretebilecek yöntemler geliştirmek için yoğun çaba harcamaktadır. Her zaman daha hızlı ve optimal ve/veya optimalden minimum sapmayla çözüme ulaşmayı sağlayacak yöntemlerin önerilmesi ile ilgili literatür çalıșmaları artarak devam etmektedir. GSP'ni bu kadar özel yapan olgu ise teorik ve endüstriyel bir çok problem için temel model niteliği taşımasıdır. GSP'nin NP-Zor sınıfında yer alan kombinasyonel bir problem olması da onu araştırmacılar için çekici yapmaktadır.
Bu çalışmada, GSP için başlangıç çözümü elde etmek için UP'lerine başlangıç çözümü üreten yaklaşımları temel alan bir sezgisel önerilmektedir. UP, AP ve GSP arasındaki benzerlikler üzerinden hareketle yeni çözüm yaklaşımları sunulmaya çalışılmıştır. Bu bağlamda, UP için başlangıç çözüm üretebilecek TPORT algoritması kullanılarak GSP başlangıç çözümleri elde edilmektedir. Bu çıktılarla GSP çözüm sezgiselleri kullanılarak GSP için hızlı ve etkin çözümler bulunması hedeflenmektedir.

Çalışmanın bilimsel yazın başlığında UP ve GSP ile ilgili bilimsel yazın kısaca sunulmuștur. Araştırmanın yöntemi bașlığında kısaca En Yakın Komşu, 2-Opt ve TPORT algoritmaları açıklanmıștır. Analiz çalıșması ve bulgular başlığında önerilen yöntem ve En Yakın Komşu algoritması ve bu yöntemlerin ürettiği çlktıların 2-Opt ile geliștirilmesi ile elde edilen çözümler karşılaştırılmıştır.

GSP tanımlanması ve anlatılması kolay, ancak çözümü oldukça zor bir problemdir. Küçük boyutlu problemler için kesin yöntemlerle çözümlere erişmek mümkündür. Ancak problem boyutları büyümeye bașladığında kesin yöntemlerle çözüme erişmek imkansız hale gelmektedir. GSP'nin bilimsel yazında NP-Zor sınıfında yer alan bir problem olduğu gösterilmiştir. Yöneylem araştırması alanında klasik bir problem olan GSP yüzyılı așkın bir 
süredir araștırmacıların en çok ilgisini çeken problemlerden birisi olmayı sürdürmüștür ve sürdürmektedir. $\mathrm{Bu}$ nedenle GSP yazınının büyük bölümü sezgisel ve metasezgisel yaklaşımlarla GSP çözümlerine adanmıştır. Sezgisel ve metasezgisellerin yanında farklı yapısal yaklaşımlarla da GSP için çözüm arayışları vardır. Sezgisellerin kullanılmasıyla optimal ve/veya optimale yakın çözümlere makul sürelerde ulaşılabilmektedir [6]. Bilimsel yazının çok büyük bölümü GSP çözümü için sezgisel ve/veya metasezgisellere ayrıldığı için tüm yazının ortaya konması olası değildir. $\mathrm{Bu}$ noktada, genetik algoritma [7-8], akışkan genetik algoritma [9], evrimsel hesaplamaya dayalı harmoni arama algoritması [10], parçacık sürü optimizasyonu [11], karınca kolonisi optimizasyonu [12], tabu arama [13], benzetimli tavlama [14] GSP'nin çözümünde sezgisel ve metasezgisel yöntemlerin kullanılmasına örnek olarak verilebilir.

Halim ve Ismail [15] en yakın komşu (EYK), genetik algoritma (GA), benzetimli tavlama, karınca kolonisi optimizasyonu (ACO) ve ağaç fizyolojisi optimizasyon algoritmalarının (TPO) GSP çözüm performanslarını karşılaştırmıştır. Antosiewicz vd. [16] GSP'nin çözümü için altı adet metasezgisel yöntemi karşılaştırmıştır. Yapılan karşılaștırma sonucunda benzetimli tavlama en iyi çözümleri bulurken, tabu arama düşük varyanslı hızlı sonuçlar üretmiştir. Chitty [17] büyük boyutlu GSP test problemlerinin çözümü için Karınca Kolonisi Optimizasyonu (ACO) yöntemini çözüm yaklaşımı olarak kullanmıştır. Karagül vd. [18] tarafından araç rotalama problemleri için bașlangıç çözüm yaklaşımları önerilmiştir. Szabo [19] tarafından GSP problemlerinin benzetimli tavlama çözümü için üç farklı başlangıç çözümü ile performans analizleri yapılmış ve benzetimli tavlama yaklaşımının hangi başlangıç çözümü ile daha iyi sonuçlar ürettiği analiz edilmiştir.

Bu çalışmada önerilen TPORT yöntemi, En Yakın Komşu (EYK) algoritması ile karşılaştırılmıştır. GSP için geliştirilmiş bir çok başlangıç çözümü üreten algoritma bilimsel yazında yer almaktadır. EYK ile TPORT uygulama ve çözüm yaklașımı açısından benzerlik göstermektedir. Her ikisi de oldukça basit ve hızlıdır. Adil bir karşılaştırma sağlanmak istendiği için özellikle çözüm süreleri açısından EYK seçiminin uygun olacağg düşünülmüştür. Her iki yöntemin ürettiği çözümler GSP bașlangıç çözümleri olarak ele alınmıș ve 2-Opt yaklaşımı ile geliștirilen çözümler üzerinden de karşılaştırmalar yapılmıştır. Analizler iki grup test problemi üzerinde yapılmıştır.

\section{Materyal ve Metot}

$\mathrm{Bu}$ çalıșmada önerilen yöntem TPORT algoritması ile elde edilen GSP başlangıç çözümleri 2-Opt algoritması ile geliștirilmiștir. Aynı problemler En Yakın Komşu algoritması kullanılarak da çözülmüş ve yine elde edilen başlangıç çözümler 2-Opt algoritması ile geliştirilmiştir. Önerilen yöntemin detaylarına geçmeden önce En Yakın Komşu ve 2-Opt algoritmaları kısaca açıklanacaktır. Daha sonra önerilen TPORT algoritması ortaya konulacaktır.

\subsection{En Yakın Komşu Algoritması}

En yakın komşu algoritması, GSP'yi çözmek için kullanılan ilk algoritmalardan biridir. Gezgin satıcı, rastgele bir şehirden başlar ve tüm şehirler ziyaret edilinceye kadar bulunduğu şehirden sonra ona en yakın şehri ziyaret eder. Hızlı bir şekilde uygun bir Hamilton turu bulur ancak bulunan çözüm optimal değildir. EYK algoritmasının adımları aşağıda özetlenmiștir [20-23];

A1. Boş rota dizisi oluşturulur, başlangıç dügümü belirlenir. Belirlenen düğüm rota dizisine atanır.

A2. İlk düğümden diğer düğümlere olan uzaklıklar belirlenir.

A3. Belirlenen uzaklıklar arasında en kısa olanı seçilir ve ikinci düğüm olarak rota dizisine atanır.

A4. Tüm dügümler tamamlanana kadar Adım 2 ve Adım 3 tekrar edilir.

Atanan düğümler sırasıyla rotayı oluşturur.

\subsection{2-0pt Algoritması}

$\mathrm{Bu}$ algoritma, farklı başlangıç çözüm algoritmaları ile elde edilen rotaların iyileştirilmesi için Croes tarafından 1958 yılında geliștirilmiştir[24]. Literatürde GSP üzerine yapılan pek çok çalıșmada 2-Opt algoritması hem çözüm yöntemi hem de tur geliştirici bir sezgisel olarak kullanılmıştır. 2-0pt algoritmasının adımları aşağıda verilmiștir [20, 22, 25-27];

A1. Rastsal olarak rotada düğüm çiftleri belirlenir.

A2. Rota bozulmayacak şekilde, düğüm çiftlerinin bağlantıları değiştirilir. 


\section{DEÜ FMD 21(63), 819-832, 2019}

A3. Yeni olușan rota önceki rotaya göre daha kısa mesafeli ise düğüm çiftlerine karşı gelen kenarlar yerlerinde kalır, maliyet tasarrufu sağlanamamıșsa düğüm çiftleri eski yerlerine alınır

Takip eden bölümde önerilen çözüm yaklaşımının detayları sunulmuştur.

\section{3. Önerilen Cözüm Yöntemi: TPORT}

Önerilen çözüm yaklaşımı UP için başlangıç çözümleri üreten bir sezgisel bakış açısıyla üretilmiștir. Bu nedenle aynı zamanda UP için başlangıç çözüm üretme potansiyeline sahip olduğu ileri sürülebilir. EK-1'de TPORT yaklaşımının Matlab kodu açık bir șekilde verilmiștir. Ancak bu kodun bazı bileșenleri, veri dosyasının okunması, uzaklık matrisinin hesaplanması ve 2-Opt fonksiyonları okuyucu tarafından geliştirilebilir ve/veya web üzerinde yapılacak kısa bir araştırma ile En Yakın Komşu algoritması da dahil olmak üzere elde edilebilir.

TPORT algoritması GSP için başlangıç çözümleri üretmek üzere tasarlanmıștır. Bu yaklaşımın çıkıș noktası GSP uzaklık matrisinin bir ulaștırma tablosu gibi ele alınarak, her bir satırının toplam değerleri bulunarak bu
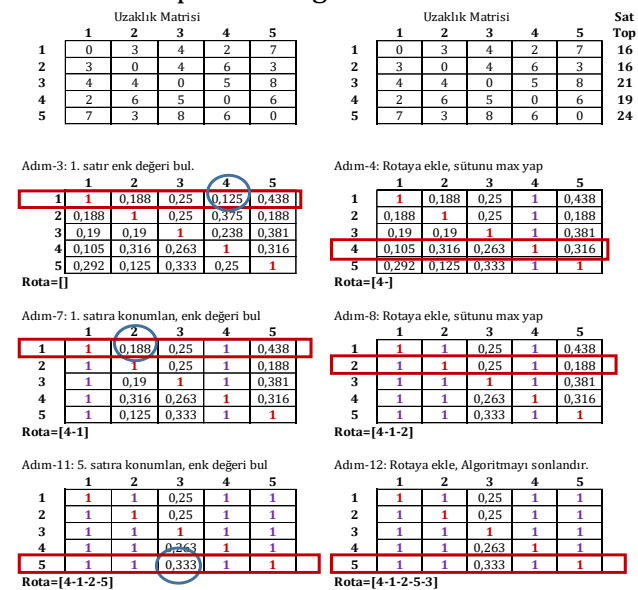

toplamlara göre satırların normalizasyonu ile elde edilen bir matris üzerinden GSP turunun oluşturulması düşüncesidir. $\mathrm{Bu}$ yaklaşım bilimsel yazındaki GSP bașlangıç çözüm yaklaşımlarından elde edilen çözüm matrisi ve matris üzerinden GSP turunun elde edilmesi süreci ile farklılık gösterir.

Önerilen yöntemin daha iyi anlaşılabilmesi için küçük bir problem üzerinden adımlar açılanmaya çalışılacaktır. Yöntemin çözüm așamalarını göstermek için Burkardt [28] tarafından hazırlanan 5 ve 15 düğümlü iki GSP kullanılmıștır. Beș dügümlü problem üzerinde çözüm aşamaları örneklenmiștir. Beş dügümlü örnek GSP probleminin uzaklık matrisi ve çözüm așamaları Şekil 1'de gösterilmektedir. Onbeș dügümlü problemin ise sadece bilgisayar ile çözümü verilmiştir. Onbeş düğümlü GSP için xy koordinatları ve uzaklık matrisi Tablo 1'de sunulmaktadır. Bilgisayar ile elde edilen çözüm ise Tablo 2'te verilmiștir. 5 düğümlü GSP için çözüm adımları Şekil 1'den takip edilebilecek şekilde verilmiştir.
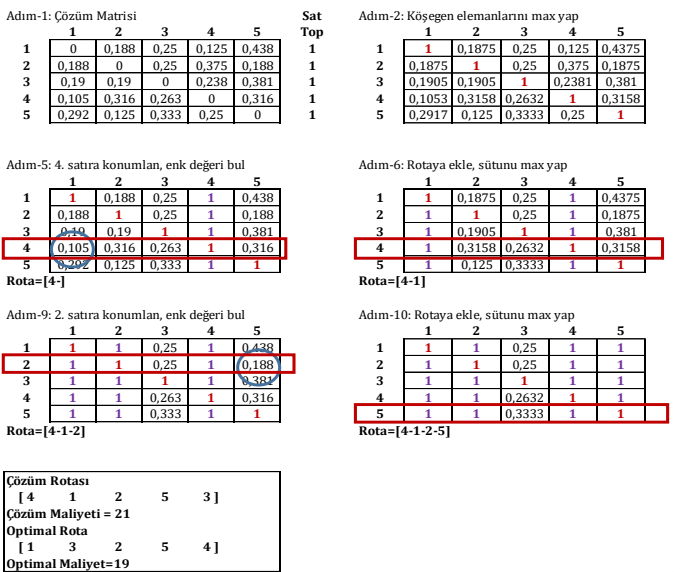

Şekil 1. Beş düğümlü örnek problem uzaklık matrisi ve çözüm aşamaları

Algoritma Verisinin Okunması ve Çözüm Matrisinin Hazırlanması: GSP koordinat verileri okunarak, uzaklık matrisi hesaplanır veya doğrudan uzaklık matrisi elde edilir. Uzaklık matrisinin her satırı için toplam değerler hesaplanır.
Adım 1: Her satır toplamı ilgili satırın elemanlarına oranlanır. Tüm satırlar için bu işlem yapıldığında Çözüm Matrisi elde edilmiş olur.

Adım 2: Çözüm Matrisinin köșegen elemanları 1 değeri ile değiştirilir böylece köșegen değerleri maksimum yapılmıș olur. 
Adım 3: Cözüme bașlamak için Çözüm matrisinin 1. satırına bakılır ve satırdaki en küçük değerli eleman bulunur. Şekil 1, Adım 3 incelendiğinde 1. Satırdaki enk eleman 4. Sütuna karşllık gelen 0,125 değeridir.

Adım 4: Adım 3'te bulunan en küçük değerli eleman 4. sütunda yer aldığı için 4. sütun tamamı 1 değeri ile doldurulur. Rota dizisine [4] eklenir.

Adım5: 4. satıra konumlanılır ve 4. satırdaki en küçük değerli eleman aranır. Örnek için en küçük değer 0,105 ile 1. sütuna denk düșer.

Adım 6: Rotaya 1 eklenir ve 1 . Sütun 1 ile doldurulur. Böylece Rota dizisi [4-1] olur.

Adım 7: 1. Satıra konumlanılır ve en küçük değerli eleman bulunur, örnek için bu değer 0,188 olur. Bu değer 2 sütununa karşllık gelir.

Adım 8: Rota dizisine 2 eklenir ve böylece rota dizisi [4-1-2] olur. Sütun 21 değerleri ile doldurulur.
Adım 9: 2. Satıra konumlanılır ve en küçük değerli eleman bulunur. Örnek için bu değer 0,188'dir ve sütun 5'e karşıllk gelir.

Adım 10: Rota dizisine 5 eklenir ve böylece [4-12-5] elde edilir.

Adım 11: 5. satıra konumlanılır ve en küçük değerli eleman bulunur. Örnek için bu değer 0,333 olur. Bu sütun 3'e karşıllk gelir.

Adım 12: Rota dizisine 3 eklenir böylece [4-1-25-3] dizisi elde edilir. Rotaya eklenecek bașka dügüm kalmadı̆̆ için algoritma sonlanır. Böylece 5 düğümlü GSP için elde edilen çözüm rotası, Sekil 1 ve TPORT algoritma adımları üzerinden [4-1-2-5-3] ve maliyet 21 olarak bulunmuştur. Problemin optimal çözüm rotası [1-3-2-5-4] ve maliyet 19 olarak verilmiştir.

Tablo 1 incelendiğinde onbeș düğümlü GSP için analitik xy koordinatları ve hesaplanan uzaklık matrisi verilmiştir.

Tablo 1. Onbeș düğümlü örnek problem koordinatlar ve uzaklık matrisi

\begin{tabular}{|c|c|c|c|c|c|c|c|c|c|c|c|c|c|c|c|c|}
\hline \multicolumn{2}{|c|}{ Koordinatlar } & \multicolumn{15}{|c|}{ Uzaklık Matrisi } \\
\hline $\mathrm{x}$ & $\mathrm{y}$ & 1 & 2 & 3 & 4 & 5 & 6 & 7 & 8 & 9 & 10 & 11 & 12 & 13 & 14 & 15 \\
\hline$-0,00000004$ & 0,00000004 & 0 & 29 & 82 & 46 & 68 & 52 & 72 & 42 & 51 & 55 & 29 & 74 & 23 & 72 & 45 \\
\hline$-28,87328622$ & $-0,00000087$ & 29 & 0 & 55 & 46 & 42 & 43 & 43 & 23 & 23 & 31 & 41 & 51 & 10 & 52 & 20 \\
\hline$-79,29157917$ & 21,40333076 & 82 & 55 & 0 & 68 & 46 & 55 & 23 & 43 & 41 & 29 & 79 & 20 & 65 & 31 & 51 \\
\hline$-14,65773817$ & 43,38954970 & 46 & 46 & 68 & 0 & 82 & 14 & 72 & 31 & 62 & 42 & 21 & 51 & 51 & 43 & 65 \\
\hline$-64,74726053$ & $-21,89817134$ & 68 & 42 & 46 & 82 & 0 & 74 & 23 & 52 & 20 & 46 & 82 & 58 & 46 & 66 & 23 \\
\hline$-29,05846931$ & 43,21672877 & 52 & 43 & 55 & 14 & 74 & 0 & 61 & 23 & 55 & 31 & 32 & 37 & 51 & 29 & 59 \\
\hline$-72,07853197$ & $-0,18158346$ & 72 & 43 & 23 & 72 & 23 & 61 & 0 & 42 & 23 & 31 & 78 & 37 & 51 & 46 & 32 \\
\hline$-36,03664897$ & 21,61354829 & 42 & 23 & 43 & 31 & 52 & 23 & 42 & 0 & 32 & 15 & 37 & 32 & 32 & 31 & 37 \\
\hline$-50,48083829$ & $-7,37447224$ & 51 & 23 & 41 & 62 & 20 & 55 & 23 & 32 & 0 & 29 & 62 & 46 & 29 & 51 & 10 \\
\hline$-50,58590268$ & 21,58819661 & 55 & 31 & 29 & 42 & 46 & 31 & 31 & 15 & 29 & 0 & 51 & 20 & 41 & 23 & 37 \\
\hline$-0,13582038$ & 28,72928968 & 29 & 41 & 79 & 21 & 82 & 32 & 78 & 37 & 62 & 51 & 0 & 65 & 42 & 59 & 61 \\
\hline$-65,08656384$ & 36,06246931 & 74 & 51 & 20 & 51 & 58 & 37 & 37 & 32 & 46 & 20 & 65 & 0 & 61 & 10 & 55 \\
\hline$-21,49832607$ & $-7,31941595$ & 23 & 10 & 65 & 51 & 46 & 51 & 51 & 32 & 29 & 41 & 42 & 61 & 0 & 62 & 23 \\
\hline$-57,56872447$ & 43,25055624 & 72 & 52 & 31 & 43 & 66 & 29 & 46 & 31 & 51 & 23 & 59 & 10 & 62 & 0 & 60 \\
\hline$-43,07002585$ & $-14,55483969$ & 45 & 20 & 51 & 65 & 23 & 59 & 32 & 37 & 10 & 37 & 61 & 55 & 23 & 60 & 0 \\
\hline
\end{tabular}


DEÜ FMD 21(63), 819-832, 2019

Tablo 2. Onbeș düğümlü örnek problem çözüm matrisi ve GSP rota ve maliyeti

\begin{tabular}{|c|c|c|c|c|c|c|c|c|c|c|c|c|c|c|c|}
\hline & 1 & 2 & 3 & 4 & 5 & 6 & 7 & 8 & 9 & 10 & 11 & 12 & 13 & 14 & 15 \\
\hline 1 & 1 & 0,04 & 0,11 & 0,06 & 0,09 & 0,07 & 0,1 & 0,06 & 0,07 & 0,07 & 0,04 & 0,1 & 0,03 & 0,1 & 0,06 \\
\hline 2 & 0,06 & 1 & 0,11 & 0,09 & 0,08 & 0,08 & 0,08 & 0,05 & 0,05 & 0,06 & 0,08 & 0,1 & 0,02 & 0,1 & 0,04 \\
\hline 3 & 0,12 & 0,08 & 1 & 0,1 & 0,07 & 0,08 & 0,03 & 0,06 & 0,06 & 0,04 & 0,11 & 0,03 & 0,09 & 0,05 & 0,07 \\
\hline 4 & 0,07 & 0,07 & 0,1 & 1 & 0,12 & 0,02 & 0,1 & 0,04 & 0,09 & 0,06 & 0,03 & 0,07 & 0,07 & 0,06 & 0,09 \\
\hline 5 & 0,09 & 0,06 & 0,06 & 0,11 & 1 & 0,1 & 0,03 & 0,07 & 0,03 & 0,06 & 0,11 & 0,08 & 0,06 & 0,09 & 0,03 \\
\hline 6 & 0,08 & 0,07 & 0,09 & 0,02 & 0,12 & 1 & 0,1 & 0,04 & 0,09 & 0,05 & 0,05 & 0,06 & 0,08 & 0,05 & 0,1 \\
\hline 7 & 0,11 & 0,07 & 0,04 & 0,11 & 0,04 & 0,1 & 1 & 0,07 & 0,04 & 0,05 & 0,12 & 0,06 & 0,08 & 0,07 & 0,05 \\
\hline 8 & 0,09 & 0,05 & 0,09 & 0,07 & 0,11 & 0,05 & 0,09 & 1 & 0,07 & 0,03 & 0,08 & 0,07 & 0,07 & 0,07 & 0,08 \\
\hline 9 & 0,1 & 0,04 & 0,08 & 0,12 & 0,04 & 0,1 & 0,04 & 0,06 & 1 & 0,05 & 0,12 & 0,09 & 0,05 & 0,1 & 0,02 \\
\hline 10 & 0,11 & 0,06 & 0,06 & 0,09 & 0,1 & 0,06 & 0,06 & 0,03 & 0,06 & 1 & 0,11 & 0,04 & 0,09 & 0,05 & 0,08 \\
\hline 11 & 0,04 & 0,06 & 0,11 & 0,03 & 0,11 & 0,04 & 0,11 & 0,05 & 0,08 & 0,07 & 1 & 0,09 & 0,06 & 0,08 & 0,08 \\
\hline 12 & 0,12 & 0,08 & 0,03 & 0,08 & 0,09 & 0,06 & 0,06 & 0,05 & 0,07 & 0,03 & 0,11 & 1 & 0,1 & 0,02 & 0,09 \\
\hline 13 & 0,04 & 0,02 & 0,11 & 0,09 & 0,08 & 0,09 & 0,09 & 0,05 & 0,05 & 0,07 & 0,07 & 0,1 & 1 & 0,11 & 0,04 \\
\hline 14 & 0,11 & 0,08 & 0,05 & 0,07 & 0,1 & 0,05 & 0,07 & 0,05 & 0,08 & 0,04 & 0,09 & 0,02 & 0,1 & 1 & 0,09 \\
\hline 15 & 0,08 & 0,03 & 0,09 & 0,11 & 0,04 & 0,1 & 0,06 & 0,06 & 0,02 & 0,06 & 0,11 & 0,1 & 0,04 & 0,1 & 1 \\
\hline \multicolumn{16}{|c|}{ Çözüm Rotası / Çözüm Maliyeti: 284} \\
\hline & 13 & 2 & 15 & 9 & 5 & 7 & 3 & 12 & 14 & 10 & 8 & 6 & 4 & 11 & 1 \\
\hline \multicolumn{16}{|c|}{ Optimal Rota / Optimal Maliyet: 284} \\
\hline & 1 & 13 & 2 & 15 & 9 & 5 & 7 & 3 & 12 & 14 & 10 & 8 & 6 & 4 & 11 \\
\hline
\end{tabular}

Tablo 2 incelendiğinde, TPORT yaklaşımı için kullanılan çözüm matrisi verilmiştir. Tablo 2'ün devamında TPORT kodu ile elde edilen çözüm rotası [13-2-15-9-5-7-3-12-14-10-8-6-4-11-1] ve buna ait hesaplanan maliyet 284'tür. Aynı şekilde problemin alındığı kaynakta [28] optimal çözüm rotası [1-13-2-15-9-5-7-3-12-14-10-8-6$4-11]$ ve optimal maliyet 284 olarak verilmiștir. Beş düğümlü ve onbeş dügümlü iki problem incelendiğinde; TPORT yaklaşımında ilk problem için optimalden sapma \%10,52 gerçekleşirken, onbeş düğümlü GSP için optimal çözüm bulunmuştur. Önerilen TPORT yaklaşımı için Matlab kodu verilmiș, aynı zamanda hesap tablosu ile beş düğümlü bir GSP ile yaklaşımın tüm detayları adım adım anlatılmıștır. Ayrıca onbeş düğümlü bir GSP ile bilgisayar ile TPORT yaklaşımının çözümü verilmiştir. Bu noktadan sonra önerilen çözüm yaklaşımının test problemleri üzerindeki performansının araștırılmasına geçilebilir.

\section{Bulgular}

TPORT yaklașımının algoritması ve örnek problem uygulamaları bir önceki bölümde verilmiştir. Önerilen yöntemin analizi için iki ayrı test problemi grubu kullanılmıştır. İlk grup problemler Antosiewicz vd. [16] makalesinden kișisel iletișim ile alınmıștır. $\mathrm{Bu}$ problem grubundaki 6 problem orijinal olarak makalenin yazarları tarafından üretilmiş son iki problem ise TSPLIB [29] kaynağından alınmıștır. İkinci grup problemler doğrudan TSPLIB'den seçilmiștir. Birinci grup problemler küçük boyutlu problemler olarak değerlendirilebilir. İkinci grupta yer alan problemler ise küçük, orta ve büyük problemler olarak sınıflandırılmıștır.

Yapılan tüm analizler Matlab 2016b paket programında Windows 10 ișletim sistemi yüklü Intel Core i7-4800MQ, $2.70 \mathrm{GHz}, 16 \mathrm{MB}$ dizüstü bilgisayarda tek çekirdek ile gerçeklenmiştir.

TPORT yaklaşımının analizi için bu iki grup problem iki așamada analiz edilmiștir. İlk așamada önerilen yöntemin ürettiği çözümler başlangıç GSP çözümleri olarak değerlendirilmiștir. $\mathrm{Bu}$ çözümler 2-Opt algoritması ile geliştirilmiştir. Aynı test problemleri En Yakın Komşu algoritması (EYK) ile çözülmüş ve elde edilen çözümler 2-Opt algoritması ile geliştirilmiştir. Önerilen yöntem ve EYK algoritması uzaklık maliyeti ve benzetim süresi performansları açısından karşılaştırılarak analiz edilmiştir. Tablo 3'te A, B, C, D, F, G, H ve Opt olarak kodlanan ifadelerin açılamaları verilmiştir. 
DEU FMD 21(63), 819-832, 2019

Tablo 3. Analiz tablolarında kullanılan kisaltmalar

\begin{tabular}{ll}
\hline Kod & Açılama \\
\hline A & TPORT Çözümü \\
B & TPORT+2-Opt Çözümü \\
C & EYK Çözümü \\
D & EYK+2-Opt Çözümü \\
E & TPORT Süre (sn) \\
F & TPORT sonrası 2-Opt Süre (sn) \\
G & EYK Süre (sn) \\
H & EYK sonrası 2-Opt Süre (sn) \\
Opt & Optimal Çözüm \\
\hline
\end{tabular}

Tablo 4. Küçük boyutlu problemlere ilişsin çözüm performansları

\begin{tabular}{ccccccc}
\hline No & P. Adı & Opt & A & B & C & D \\
\hline 1 & $20(a)$ & 397 & 518 & 402 & 407 & 404 \\
2 & $20(\mathrm{~b})$ & 367 & 435 & 367 & 380 & 367 \\
3 & $50(\mathrm{a})$ & 560 & 802 & 598 & 683 & 584 \\
4 & $50(\mathrm{~b})$ & 571 & 706 & 590 & 614 & 587 \\
5 & $80(\mathrm{a})$ & 709 & 910 & 735 & 801 & 722 \\
6 & $80(\mathrm{~b})$ & 687 & 861 & 703 & 770 & 697 \\
7 & att48 & 333 & 408 & 345 & 373 & 350 \\
8 & eil76 & 538 & 660 & 565 & 608 & 554 \\
\hline
\end{tabular}

Tablo 5 incelendiğinde A çözüm yaklaşımının saniye olarak değerleri E sütununda gösterilmiştir. Aynı şekilde diğer sütunlarda da diğer yaklașımların çözüm süreleri saniye olarak verilmiștir. boyutlu problemler için optimal, A, B, C ve D çözümleri yer almaktadır.

Tablo 5. Küçük problemler için çözüm süreleri

\begin{tabular}{cccccccc}
\hline No & P.Adl & $\mathrm{E}$ & $\mathrm{F}$ & $\mathrm{G}$ & $\mathrm{H}$ & $\mathrm{Z} 1=\mathrm{E}+\mathrm{F}$ & $\mathrm{Z} 2=\mathrm{G}+\mathrm{H}$ \\
\hline 1 & 20 (a) & $37,03 \times 10^{-4}$ & $6,53 \times 10^{-4}$ & $20,76 \times 10^{-4}$ & $36,77 \times 10^{-4}$ & $43,56 \times 10^{-4}$ & $57,53 \times 10^{-4}$ \\
2 & 20 (b) & $35,02 \times 10^{-4}$ & $5,96 \times 10^{-4}$ & $15,06 \times 10^{-4}$ & $16,84 \times 10^{-4}$ & $40,98 \times 10^{-4}$ & $31,90 \times 10^{-4}$ \\
3 & 50 (a) & $37,03 \times 10^{-4}$ & $9,75 \times 10^{-4}$ & $71,12 \times 10^{-4}$ & $88,99 \times 10^{-4}$ & $46,78 \times 10^{-4}$ & $160,11 \times 10^{-4}$ \\
4 & 50 (b) & $37,82 \times 10^{-4}$ & $8,55 \times 10^{-4}$ & $79,01 \times 10^{-4}$ & $25,62 \times 10^{-4}$ & $46,37 \times 10^{-4}$ & $104,63 \times 10^{-4}$ \\
5 & 80 (a) & $43,99 \times 10^{-4}$ & $11,35 \times 10^{-4}$ & $196,21 \times 10^{-4}$ & $12,83 \times 10^{-4}$ & $55,34 \times 10^{-4}$ & $209,04 \times 10^{-4}$ \\
6 & 80 (b) & $50,48 \times 10^{-4}$ & $12,10 \times 10^{-4}$ & $196,59 \times 10^{-4}$ & $56,76 \times 10^{-4}$ & $62,58 \times 10^{-4}$ & $253,35 \times 10^{-4}$ \\
7 & att48 & $38,12 \times 10^{-4}$ & $9,99 \times 10^{-4}$ & $97,54 \times 10^{-4}$ & $11,62 \times 10^{-4}$ & $48,11 \times 10^{-4}$ & $109,16 \times 10^{-4}$ \\
8 & eil76 & $41,23 \times 10^{-4}$ & $11,09 \times 10^{-4}$ & $176,29 \times 10^{-4}$ & $11,94 \times 10^{-4}$ & $52,32 \times 10^{-4}$ & $188,23 \times 10^{-4}$ \\
\hline
\end{tabular}

Tablo 6'de küçük test problemleri için göreli karşılaştırmalar tablosu verilmiştir. Bu tabloda Opt sütununda optimal çözüm ile diğer yaklașımların göreli karșılaștırmaları için 1 her problem için referans değer olarak kullanılmıștır. Tablo 6, denklem 1 ile hesaplanmıştır.

$$
\begin{aligned}
& \left(\frac{\text { Çözüm }}{\text { Optimal Çözüm }}\right)=\frac{\text { Cözüm Değeri }}{\text { Optimal Dĕ̆er }} \times 100 \\
& \text { Çözüm : } A, B, C, D
\end{aligned}
$$

Bu durumda optimal çözüm 1 ile ifade edilirse tablodaki oranlardan 1 'den ne kadar uzak ise çözüm performansı o kadar kötüye gidiyor demektir. Bu bakış açısı ile Tablo 6 ortalama satırına bakıldığında optimalden TPORT yaklaşımı \%27 ortalama ile EYK algoritması \%11 sapma ile çözüm bulmuştur. Ancak her iki yönteme de 2-Opt uygulanarak elde edilen çözüm değerlerine bakıldığında her ikisi de \%3 sapma ile sonuca ulaşmıștır. Bu değerler de TPORT yaklaşımının iyi bir başlangıç çözüm olmaya yönelik ilk göstergeleri olduğu ileri sürülebilir. 
DEÜ FMD 21(63), 819-832, 2019

Tablo 6. Küçük problemler için çözüm performanslarının göreli karşılaştırması

\begin{tabular}{clccccc}
\hline No & P.Adl & Opt & A/Opt & B/Opt & C/Opt & D/Opt \\
\hline 1 & $20(\mathrm{a})$ & 1 & 1,30 & 1,01 & 1,03 & 1,02 \\
2 & $20(\mathrm{~b})$ & 1 & 1,19 & 1,00 & 1,04 & 1,00 \\
3 & $50(\mathrm{a})$ & 1 & 1,43 & 1,07 & 1,22 & 1,04 \\
4 & $50(\mathrm{~b})$ & 1 & 1,24 & 1,03 & 1,08 & 1,03 \\
5 & $80(\mathrm{a})$ & 1 & 1,28 & 1,04 & 1,13 & 1,02 \\
6 & $80(\mathrm{~b})$ & 1 & 1,25 & 1,02 & 1,12 & 1,01 \\
7 & att48 & 1 & 1,23 & 1,04 & 1,12 & 1,05 \\
8 & eil76 & 1 & 1,23 & 1,05 & 1,13 & 1,03 \\
\hline & Ortalama & 1 & 1,27 & 1,03 & 1,11 & 1,03 \\
\hline
\end{tabular}

Aynı bakış açısı ile Tablo 7 incelendiğinde referans değer olarak 1 alınmıştır. 1'den küçük değerler EYK ve EYK'ya uygulanan 2-Opt sürelerinin daha etkin olduğunu gösterir. Ancak 1'den büyük olan değerler TPORT çözümlerinin EYK'dan kaç kat hızlı olduğunu gösterir. $\mathrm{Bu}$ bağlamda $G / E$ sütunu için ortalama değerlere bakıldığında TPORT çözüm süreleri 2,52 kat EYK'dan hızlı sonuca gitmektedir. Aynı şekilde H/F sütunu incelendiğinde başlangıç çözümleri TPORT ve EYK için 2-Opt uygulama süreleri karşılaștırıldığında 2,5 kat ortalama olarak TPORT çözümleri daha hızlı geliştirilebilmektedir.
Tablo 7. Küçük problemler için sürelerin göreli karşılaștırması

\begin{tabular}{cllll}
\hline No & P. Adı & Ref & G/E & H/F \\
\hline 1 & $20(a)$ & 1,0 & 0,6 & 5,6 \\
2 & $20(\mathrm{~b})$ & 1,0 & 0,4 & 2,8 \\
3 & $50(a)$ & 1,0 & 1,9 & 0,9 \\
4 & $50(\mathrm{~b})$ & 1,0 & 2,1 & 3,0 \\
5 & $80(\mathrm{a})$ & 1,0 & 4,5 & 1,1 \\
6 & $80(\mathrm{~b})$ & 1,0 & 3,9 & 4,7 \\
7 & att48 & 1,0 & 2,6 & 1,2 \\
8 & eil76 & 1,0 & 4,3 & 1,1 \\
\hline & Ortalama & 1,0 & 2,52 & 2,55 \\
\hline
\end{tabular}

Tablo 4, 5, 6 ve 7 için verilen tartışmaların grafikleri Şekil 2'de a, b, c ve d şeklinde gösterilmiştir.

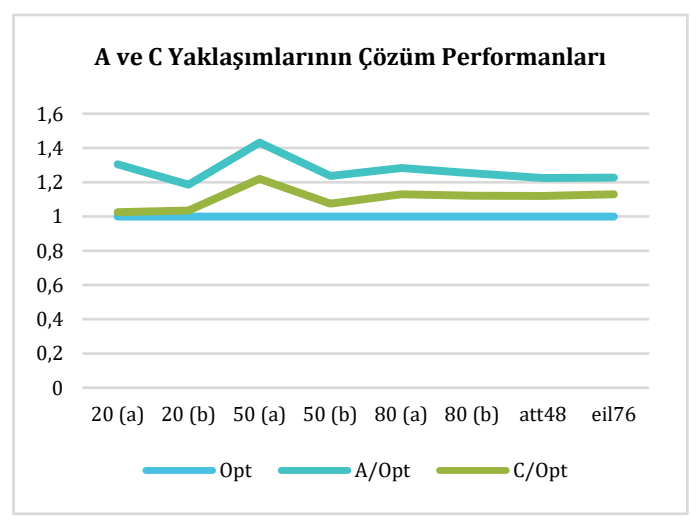

(a) Opt, A ve C Göreli Çözüm Karşılaş̧ırma

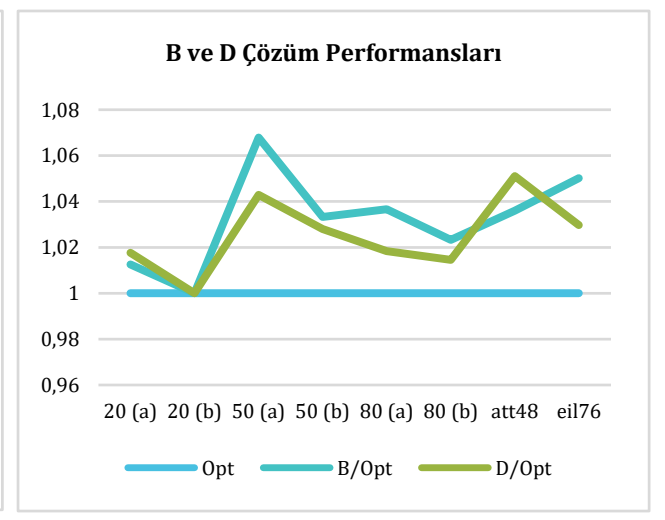

(b) B ve D'nin 2-Opt ile Göreli Çözüm Karşıllaştırması 
DEÜ FMD 21(63), 819-832, 2019

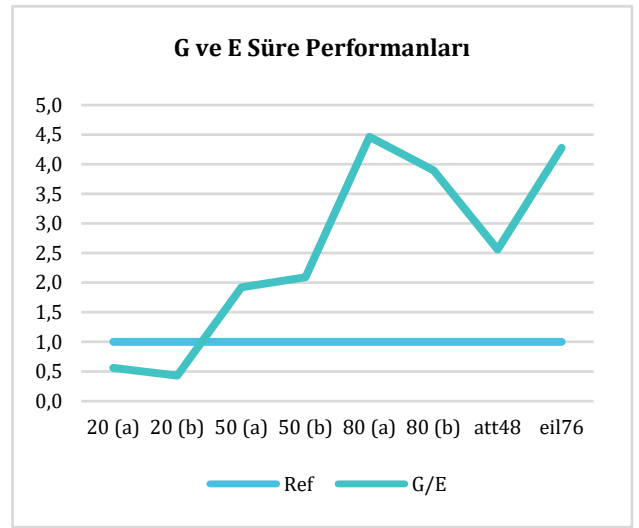

(c) G ve E Çözüm Yaklaşımlarının Göreli Süre Karşılaştırması

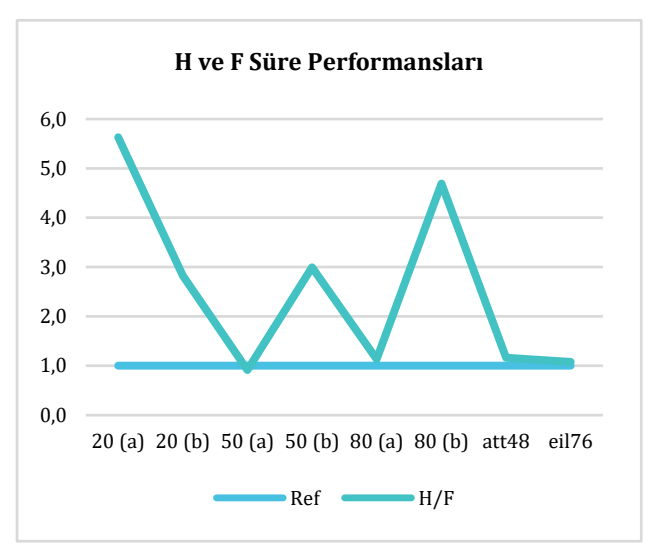

(d) H ve F yaklaşımlarının 2-Opt ile Göreli Süre Karşılaştırması

Şekil 2. Küçük problemler için performans grafikleri

Tablo 8'da TSPLIB'den seçilmiș olan küçük, orta ve büyük problemler için çözüm değerleri gösterilmiştir.

Tablo 8. TSPLIB test problemlerinin çözümleri

\begin{tabular}{clccccc}
\hline No & P.Adl & Opt & A & B & C & D \\
\hline 1 & eil51 & 426 & 563 & 440 & 482 & 434 \\
2 & berlin52 & 7542 & 8920 & 7842 & 8181 & 7711 \\
3 & st70 & 675 & 852 & 690 & 796 & 727 \\
4 & pr76 & 108159 & 153150 & 114283 & 130921 & 113404 \\
5 & rat99 & 1211 & 1566 & 1317 & 1437 & 1259 \\
6 & kroA100 & 21282 & 27015 & 22063 & 24698 & 21389 \\
7 & eil101 & 629 & 808 & 640 & 746 & 639 \\
8 & ch130 & 6110 & 7658 & 6435 & 7129 & 6414 \\
9 & ch150 & 6528 & 8150 & 6620 & 7113 & 6606 \\
10 & rat195 & 2323 & 2752 & 2392 & 2612 & 2393 \\
11 & d198 & 15780 & 18240 & 16036 & 17620 & 16033 \\
12 & a280 & 2579 & 3256 & 2740 & 3008 & 2675 \\
13 & rd400 & 15281 & 19176 & 15878 & 18431 & 15840 \\
14 & pcb442 & 50778 & 61745 & 53274 & 58950 & 52916 \\
15 & rl1323 & 270199 & 332001 & 284015 & 312845 & 280799 \\
\hline
\end{tabular}

Tablo 9'da ikinci grup test problemleri için çözüm süreleri verilmiștir ve tüm süreler saniye olarak ifade edilmiştir. Tablo 9'da Z1, TPORT ve 2-Opt çözüm sürelerinin birlikte ölçümünü, Z2 ise EYK ve 2-Opt sürelerinin birlikte ölçümünü göstermektedir. 
DEÜ FMD 21(63), 819-832, 2019

Tablo 9. TSPLIB test problemlerinin çözüm süreleri

\begin{tabular}{clcccccc}
\hline No & P.Adl & $\mathrm{E}\left(\mathrm{x} 10^{-4}\right)$ & $\mathrm{F}\left(\mathrm{x} 10^{-4}\right)$ & $\mathrm{G}\left(\mathrm{x} 10^{-4}\right)$ & $\mathrm{H}\left(\mathrm{x} 10^{-4}\right)$ & $\mathrm{Z} 1=\mathrm{E}+\mathrm{F})\left(\mathrm{x} 10^{-4}\right)$ & $(\mathrm{Z} 2=\mathrm{G}+\mathrm{H})\left(\mathrm{x} 10^{-4}\right)$ \\
\hline 1 & eil51 & 40,23 & 8.49 & 76,63 & 8,00 & 48,72 & 84,63 \\
2 & berlin52 & 38,30 & 8,14 & 79,96 & 7,52 & 46,44 & 87,48 \\
3 & st70 & 43,52 & 11,99 & 151,45 & 13,35 & 55,51 & 164,8 \\
4 & pr76 & 42,10 & 12,39 & 177,12 & 13,13 & 54,49 & 190,25 \\
5 & rat99 & 43,56 & 15,25 & 314,98 & 19,98 & 58,81 & 334,96 \\
6 & kroA100 & 40,39 & 16,20 & 286,07 & 14,84 & 56,59 & 300,91 \\
7 & eil101 & 47,75 & 16,55 & 317,93 & 20,35 & 64,30 & 338,28 \\
8 & ch130 & 43,51 & 25,50 & 459,87 & 22,46 & 69,01 & 482,33 \\
9 & ch150 & 48,05 & 28,65 & 624,67 & 26,62 & 76,7 & 651,29 \\
10 & rat195 & 49,65 & 43,08 & 1095,20 & 40,86 & $92,73^{4}$ & 1136,06 \\
11 & d198 & 49,86 & 67,94 & 1068,74 & 51,85 & 117,8 & 1120,59 \\
12 & a280 & 60,22 & 129,53 & 2876,58 & 179,14 & 189,75 & 3055,72 \\
13 & rd400 & 108,47 & 663,43 & 10257,92 & 493,11 & 771,90 & 10751,03 \\
14 & pcb442 & 103,28 & 459,09 & 12457,59 & 480,06 & 562,37 & 12937,65 \\
15 & r1323 & 1139,07 & 22065,85 & 512582,86 & 19366,55 & 23204,92 & 531949,41 \\
\hline
\end{tabular}

Tablo 10'de göreli çözüm performansları verilmiştir. Burada her bir problem için diğerine göre üstün olan çözüm yaklaşımının değeri koyu renkli olarak işaretlenmiştir. Tablo 10'deki son satırda yer alan ortalamalar, incelendiğinde TPORT yaklașımı \%26, EYK sezgiseli ise \%16 oranında optimalden uzak çözümlere erişmiştir. Ancak her iki yönteme 2-Opt uygulanarak elde

Tablo 10. TSPLIB test problemlerinin göreli çözüm oranları

\begin{tabular}{cllllll}
\hline No & P.Adl & Opt & A & C & B & D \\
\hline 1 & eil51 & 1,00 & 1,32 & 1,13 & 1,03 & 1,02 \\
2 & berlin52 & 1,00 & 1,18 & 1,08 & 1,04 & 1,02 \\
3 & st70 & 1,00 & 1,26 & 1,18 & 1,02 & 1,08 \\
4 & pr76 & 1,00 & 1,42 & 1,21 & 1,06 & 1,05 \\
5 & rat99 & 1,00 & 1,29 & 1,19 & 1,09 & 1,04 \\
6 & kroA100 & 1,00 & 1,27 & 1,16 & 1,04 & 1,01 \\
7 & eil101 & 1,00 & 1,28 & 1,19 & 1,02 & 1,02 \\
8 & ch130 & 1,00 & 1,25 & 1,17 & 1,05 & 1,05 \\
9 & ch150 & 1,00 & 1,25 & 1,09 & 1,01 & 1,01 \\
10 & rat195 & 1,00 & 1,18 & 1,12 & 1,03 & 1,03 \\
11 & d198 & 1,00 & 1,16 & 1,12 & 1,02 & 1,02 \\
12 & a280 & 1,00 & 1,26 & 1,17 & 1,06 & 1,04 \\
13 & rd400 & 1,00 & 1,25 & 1,21 & 1,04 & 1,04 \\
14 & pcb442 & 1,00 & 1,22 & 1,16 & 1,05 & 1,04 \\
15 & rl1323 & 1,00 & 1,23 & 1,16 & 1,05 & 1,04 \\
\hline \multirow{2}{*}{ Ortalama } & 1,00 & 1,26 & 1,16 & 1,04 & 1,03 \\
\hline
\end{tabular}

edilen çözümlerde sırasıyla \%4 ve \%3 sapmalar elde edilmiştir. Burada EYK+2-Opt yaklaşımının TPORT+2-Opt yaklaşımına göre ortalamada $\% 1$ daha başarılı olduğu görülmektedir. Ancak bu fark çözüm süreleri gözönüne alındığında TPORT+2-Opt yaklașımın rekabetçi bir çözüm yaklaşımı olduğu iddiasını çürütmez. 
Tablo 11 incelendiğinde iki yöntem için göreli karşılaștırmalar verilmiştir. Burada G/E sütununun ortalaması incelendiğinde TPORT yaklaşımı EYK yaklaşımından ortalama olarak 54 kat daha hızlı çözüme gittiği gözlenmektedir. $\mathrm{Bu}$ problemler için TPORT yaklaşımına uygulanan 2-Opt ise EYK yaklaşımına uygulanan
2-Opt çözüm süresinden ortalama olarak fark oluşturmamıştır. Son sütun olan Z2/Z1 sütunu önerilen ve referans alınan yöntemlerin 2-0pt rota geliștirme süreleri dahil olmak üzere toplam zaman açısından karşılaştırıldığında ortalama olarak önerilen yaklaşımın 9,30 kat daha hızlı olduğu görülmektedir.

Tablo 11. TSPLIB test problemlerinin göreli çözüm süreleri oranları

\begin{tabular}{clcccc}
\hline No & P.Adl & Opt & G/E & H/F & Z2/Z1 \\
\hline 1 & eil51 & 1,00 & 1,90 & 0,94 & 1,74 \\
2 & berlin52 & 1,00 & 2,09 & 0,92 & 1,88 \\
3 & st70 & 1,00 & 3,48 & 1,11 & 2,97 \\
4 & pr76 & 1,00 & 4,21 & 1,06 & 3,49 \\
5 & rat99 & 1,00 & 7,23 & 1,31 & 5,70 \\
6 & kroA100 & 1,00 & 7,08 & 0,92 & 5,32 \\
7 & eil101 & 1,00 & 6,66 & 1,23 & 5,26 \\
8 & ch130 & 1,00 & 10,57 & 0,88 & 6,99 \\
9 & ch150 & 1,00 & 13,00 & 0,93 & 8,49 \\
10 & rat195 & 1,00 & 22,06 & 0,95 & 12,25 \\
11 & d198 & 1,00 & 21,44 & 0,76 & 9,51 \\
12 & a280 & 1,00 & 47,77 & 1,38 & 16,10 \\
13 & rd400 & 1,00 & 94,57 & 0,74 & 13,93 \\
14 & pcb442 & 1,00 & 120,63 & 1,05 & 23,01 \\
\hline & rl1323 & 1,00 & 450,00 & 0,88 & 22,92 \\
\hline \multirow{2}{*}{ Ortalama } & & 54,18 & 1,00 & 9,30 \\
\hline
\end{tabular}

Analiz sonuçları bir bütün olarak değerlendirildiğinde hem küçük hem de büyük problemler için EYK+2-Opt yaklaşımının rekabetçi bir yaklașım olduğu değerlendirilebilir. Bununla birlikte çözüm süreleri açısından yapılan karşılaştırmalarda TPORT yaklaşımının EYK algoritmasından üstün olduğu; EYK algoritması çözüm süresi üstel bir eğilim izlerken TPORT yaklaşımın çözüm süresinin göreli olarak çok az bir değişim gösterdiği gözlenmektedir.

\section{Tartışma ve Sonuç}

Bu çalışmada GSP problemi için TPORT adı verilen yapısal bir başlangıç çözümü oluşturma yöntemi önerilmiştir. TPORT başlangıç çözümleri, EYK algoritması başlangıç çözümleri ile iki grup problem üzerinden uzaklık maliyeti ve benzetim süresi performansları açısından karşılaştırılmıștır. Ayrıca TPORT ve EYK algoritması ile elde edilen GSP çözümleri, 2-Opt ile geliştirilmiş ve tekrar uzaklık maliyeti ve benzetim süresi performansları açısından karșılaștırılmıștır. Yapılan tüm analizler TPORT yaklaşımının uzaklık maliyeti performansı açısından rekabetçi çözümler ürettiğini göstermektedir. Bununla birlikte, benzetim süresi performansları üzerinden yapılan analizler TPORT yaklaşımının EYK algoritmasına göre üstünlügünü ortaya koymaktadır.

GSP için iyi bir çözüm algoritmasının ne olduğuna yönelik açık bir soru, hızlı çözüm üreten, çok sayıda tekrar çalıştırmaya izin veren basit bir iyileştirme yöntemi uygulamanın mı yoksa üretilen çözümü önemli ölçüde iyileștiren karmaşık ve uzun süren bir yöntemi uygulamanın mı daha iyi olduğu hakkındadır. Bu çalışmada önerilen TPORT benzeri basit bir algoritma büyük ölçüde ilk çözüme 
bağlıdır, ancak EYK algoritması gibi daha karmaşık yöntemler çok daha fazla çalışma süresi alacağı için yalnızca birkaç kez uygulanabilir, böylece ele alınan çözüm uzayının örneklenmesi azalmaktadır.

Bu çalışmada hızlı çözüm üreten, çok sayıda tekrar çalıştırmaya izin veren basit bir iyileştirme yöntemi önerilerek bu alanda rekabetçi bir algoritmanın literatüre kazandırılması hedeflenmiştir. Önerilen yapısal yaklaşımın, basit ve hızlı çözüm yeteneği sayesinde yeni yapısal çözüm yaklaşımları, sezgiseller ve meta-sezgiseller ile birlikte kullanılması veya GSP çözümü dışında farklı optimizasyon alanlarına uygulanması ileriye dönük çalışma konuları olarak ele alınabilir. Farklı uygulama alanları GSP'nin temel problem olarak alındığı, çizelgeleme problemleri, araç rotalama problemleri, insansız hava araçlarının rotalanması, askeri alanlardaki bazı problemlerin çözümleri, robotların rotalama algoritmalarının geliştirilmesi gibi alanlar ele alınabilir.

\section{Kaynakça}

[1] Kuhn, H.W. 1955. The Hungarian Method for the Assignment Problem, Naval Research Logistics Quarterly, Cilt. 2, Sayı. 1-2,s. 83-97.

[2] Munkres, J. 1957. Algorithms for the Assignment and Transportation Problems, Journal of the Society for Industrial and Applied Mathematics, Cilt. 5, Sayı. 1, s. 32-38.

[3] Burkard, R.E. 1979. Travelling Salesman and Assignment Problems: A Survey, Annals of Discrete Mathematics, Cilt. 4, s. 193-215.

[4] Winston, W.L. 2003. Operations Research: Applications and Algorithms. 4th edition. Cengage Learning.

[5] Dantzig, G.B., Thapa, M.N. 1997. Linear Programming 1: Introduction. Springer-Verlang New York, USA.

[6] Ratliff, H.D., Rosenthal, A.S. 1983. Order Picking in a Rectangular Warehouse: A Solvable Case of the Traveling Salesman Problem. Operations Research, Cilt. 31, Sayı. 3, s. 507-521.

[7] Zhao, F., Li, S., Sun, J., Mei, D. 2009. Genetic Algorithm for the One-Commodity Pickup-and-Delivery Traveling Salesman Problem. Computers \& Industrial Engineering. Cilt. 56, Sayı. 4, s. 1642-1648.

[8] Joines, A., Kay, M.G., Karabacak, M.F., Karagül, K Tokat, S. 2017. Performance analysis of Genetic Algorithm Optimization Toolbox via Traveling Salesperson Problem. ss. 213-221. Sayers, W. ed. Contemporary Issues in Social Sciences and Humanities, UK, AGP Research, London.

[9] Sahin, Y., Karagül, K. 2019. Solving Travelling Salesman Problem Using Hybrid Fluid Genetic Algorithm (HFGA), Pamukkale University Journal of Engineering Sciences, Ahead of Print: PAJES-81084 DOI: $10.5505 /$ pajes.2018.81084.

[10] Karagul, K., Aydemir, E., Tokat, S. 2016. Using 2-Opt Based Evolution Strategy for Travelling Salesman Problem. An International Journal of Optimization and Control: Theories \& Applications (IJOCTA), Cilt 6, Sayı. 2, s. 103-113.

[11] Dorigo, M., Gambardella, L.M. 1997. Ant Colony System: A Cooperative Learning Approach to the Traveling Salesman Problem. IEEE Transactions on Evolutionary Computation, Cilt. 1, Sayl. 1, s. 53-66.

[12] Mavrovouniotis, M., Yang, S. 2013. Ant Colony Optimization with Immigrants Schemes for the Dynamic Travelling Salesman Problem with Traffic Factors. Applied Soft Computing. Cilt. 13, Sayı. 10, s. 4023-4037.

[13] Gendreau, M., Laporte, G., Semet, F. 1998. A Tabu Search Heuristic for the Undirected Selective
Travelling Salesman Problem. European Journal of Operational Research, Cilt. 106, Sayı. 2-3, s. 539-545.

[14] Malek, M., Guruswamy, M., Pandya, M., Owens, H. 1989. Serial and Parallel Simulated Annealing andTabu Search Algorithms for the Traveling Salesman Problem. Annals of Operations Research, Cilt. 21, Sayı. 1, s. 59-84.

[15] Halim, A.H., Ismail, I. 2017. Combinatorial Optimization: Comparison of Heuristic Algorithms in Travelling Salesman Problem. Archives of Computational Methods in Engineering, s. 1-14. DOI: $10.1002 /$ net.3230200605.

[16] Antosiewicz, M., Koloch, G., Kamiński, B. 2013. Choice of Best Possible Metaheuristic Algorithm for the Travelling Salesman Problem with Limited Computational Time: Quality, Uncertainty and Speed. Journal of Theoretical and Applied Computer Science, Cilt. 7, Sayı. 1, s. 46-55.

[17] Chitty, D. M. 2017. Applying ACO To Large Scale TSP Instances. UK Workshop on Computational Intelligence, s. 104-118. Springer, Cham. arXiv:1709.03187. DOI: 10.1007/978-3-319-669397_9.

[18] Karagul, K., Kay, M. G., Tokat, S. 2018. A New Method for Generating Initial Solutions of Capacitated Vehicle Routing Problems. Gazi University Journal of Science, Cilt. 31, Sayı. 2, s. 489-513.

[19] Szabo, J. 2016. Comparison of Methods for Generating Initial Solution for Simulated Annealing. Central European Researchers Journal, Cilt. 2, Sayı. 1, s. 37-41.

[20] Şahin, Y., Kulak, O. 2013. Depo Operasyonlarının Planlanması İçin Genetik Algoritma Esaslı Modeller. Uluslararası Alanya İşletme Fakültesi Dergisi, Cilt. 5, Sayı. 3, s. 141-153.

[21] Kızılateş, G., Nuriyeva, F. 2013. On the Nearest Neighbor Algorithms for the Traveling Salesman Problem. In: Nagamalai D., Kumar A., Annamalai A. (eds) Advances in Computational Science, Engineering and Information Technology. Advances in Intelligent Systems and Computing, vol 225. Springer, Heidelberg.

[22] Kay, M. 2016. MATLOG: Logistics Engineering Using Matlab. Mühendislik Bilimleri ve Tasarım Dergisi, Cilt. 4, Sayı. 1, s. 15-20. Retrieved from http://dergipark.gov.tr/jesd/issue/20875/224091.

[23] Matworks, File Exchange, https://www.mathworks.com/matlabcentral/ fileexchange/25542-nearest-neighbor-algorithmfor-the-travelling-salesman-problem, (Erişim Tarihi: 18.02.2019).

[24] Croes, G.A. 1958. A Method for Solving TravelingSalesman Problems. Operations Research, Cilt. 6, Sayı. 6, s. 791-812. 
DEÜ FMD 21(63), 819-832, 2019

[25] Eryavuz, M., Gencer, C. 2001. Araç Rotalama Problemine Ait Bir Uygulama. Süleyman Demirel Üniversitesi İktisadi ve İdari Bilimler Fakültesi Dergisi, Cilt. 6, Sayı. 1, s. 139-155. . Retrieved from http://dergipark.gov.tr/sduiibfd/issue/20850/223 589

[26] Kuang, E. 2012. A 2-opt-based Heuristic for the Hierarchical Traveling Salesman Problem. http://honors.cs.umd.edu/reports/kuang.pdf, (Erişim Tarihi: 18.02.2019).

[27] Sathyan, A., Boone, N., Cohen, K. 2015. Comparison of Approximate Approaches to Solving the Travelling Salesman Problem and its Application to UAV Swarming. International Journal of Unmanned UAV Swarming Systems Engineering (IJUSEng), Cilt. 3, Sayl. 1, s. 1-16.

[28] Burkardt, J. 2019. Data for the Traveling Salesperson Problem. https://people.sc.fsu.edu/ jburkardt/ datasets/tsp/tsp.html, (Erişim Tarihi: 18.02.2019).

[29] Universität Heidelberg. "Index of /software/TSPLIB95/tsp". http://comoptifi.uniheidelberg.de/ software/TSPLIB95/tsp/ (Erișim Tarihi: 18.11.2018) 
DEÜ FMD 21(63), 819-832, 2019

EK- 1. Önerilen yöntem TPORT için Matlab kodu

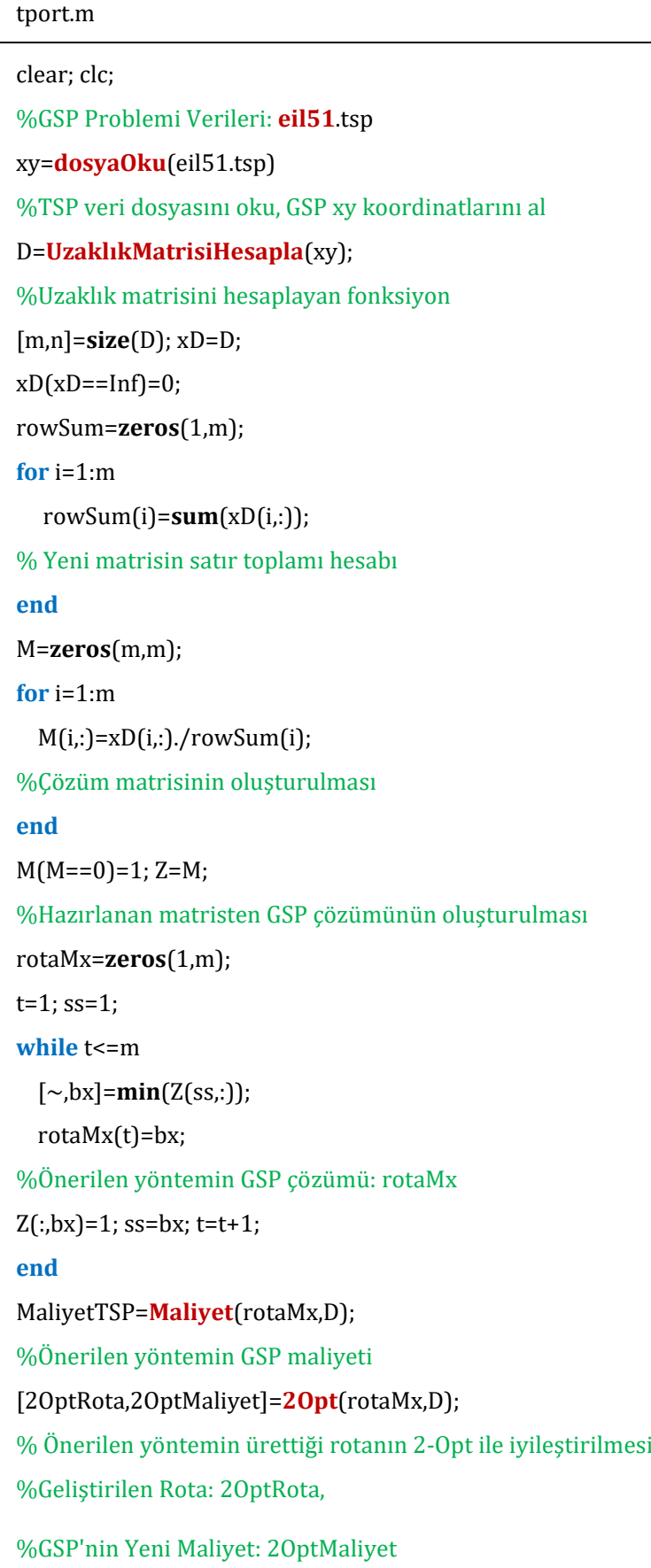

